\title{
Ensino de língua portuguesa, Lei 11.645/08 e novas tecnologias da informação e comunicação: uma proposta pedagógica antirracista para 0 ensino on-line
}

\section{Enseñanza del idioma portugués, Ley 11.645/08 y nuevas tecnologías de información y comunicación: una propuesta pedagógica antirracista para la enseñanza en línea}

\author{
Alex Santana França ${ }^{1}$
}

\begin{abstract}
Resumo
A utilização de recursos tecnológicos no ensino é uma longa e antiga discussão na área da Educação, o que, desde sempre exigiu maior aprofundamento e cuidado, mas que, certamente o recente cenário de distanciamento social resultante da pandemia mundial de Covid-19, acelerou / atropelou o processo de aplicação desses recursos digitais nas diferenciadas instituições de ensino, público e privado, básico, tecnológico e universitário para a manutenção de atividades pedagógicas à distância. Entretanto, no contexto brasileiro, essa situação expôs ainda mais a segregação étnica, social e cultural, que também afeta a educação. Diante disso, pretende-se no presente artigo apresentar estratégias pedagógicas, baseadas em teorias da afrocentricidade e do indigenismo, que sigam uma perspectiva antirracista, visando o cumprimento da Lei 11.645/08, e que utilizem ferramentas on-line familiarmente acessadas pelo público em geral.
\end{abstract}

Palavras-chave: Ensino de Língua Portuguesa. Lei 11.645/08. Novas TICs.

\section{Resumen}

El uso de recursos tecnológicos en la enseñanza es una discusión larga y antigua en el campo de la educación, que siempre ha requerido mayor profundidad y cuidado, pero que, ciertamente, el reciente escenario de distancia social resultante de la pandemia mundial de Covid-19, aceleró / atropelló el proceso de aplicación de estos recursos digitales en diferentes instituciones educativas, públicas y privadas, básicas, tecnológicas y universitarias para el mantenimiento de actividades de educación a distancia. Sin embargo, en el contexto brasileño, esta situación expuso aún más la segregación étnica, social y cultural, que también afecta la educación. Por lo tanto, el objetivo de este artículo es presentar estrategias pedagógicas, basadas en teorías de afrocentricidad e Indigenismo, que sigan una perspectiva antirracista, con el objetivo de cumplir con la Ley 11.645 / 08, y que utilicen herramientas virtuales más fáciles de acceder por el público en general.

Palabras clave: Enseñanza de la lengua portuguesa. Ley 11.645/08. Nuevas TIC.

\section{Introdução}

A educação escolar brasileira ainda apresenta uma estrutura de origem e concepção eurocêntrica, marcada por práticas segregacionistas e discriminatórias, em especial no acesso, no currículo, nas metodologias de ensino e nas estratégias de avaliação, o que se configura como algo extremamente problemático, principalmente quando se defende uma educação democrática e descolonizadora. Além disso, historicamente, o sistema brasileiro de educação concebeu e pregou 0 ensino em uma perspectiva de embranquecimento sociocultural em sentido amplo. Diante desse contexto, diferentes educadores e pesquisadores, como Muniz Sodré, Nilma Lino Gomes, Kabengele

\footnotetext{
1 Doutor em Letras. Universidade Federal da Bahia, Salvador, Bahia, Brasil. Orcid: https://orcid.org/0000-0001-6013-8835. Email: alexsfranca@yahoo.com.br
} 
Munanga e Djamila Ribeiro, defendem que a prática antirracista no Brasil é urgente e deve ocorrer nas atitudes mais cotidianas, em especial na educação.

Assim, como desenvolver nas escolas novos parâmetros que se contraponham ao modelo de sistema escolar que não tem nada a ver com as pedagogias e os métodos próprios de aprendizagem das diferentes culturas tradicionais, entendendo que os processos educativos tradicionais dos povos indígenas, por exemplo, são diferentes? Como pensar e implementar práticas educacionais que atendam aos projetos socioculturais dos povos afro-brasileiros e indígenas, concorrentes com os modelos e as perspectivas de projetos globais de escola e de educação homogeneamente eurocêntricos e colonizadores?

O presente artigo visa apresentar uma proposta de ensino de Língua Portuguesa, em uma perspectiva antirracista, visando o cumprimento da Lei 11.645, sancionada pelo presidente Luiz Inácio Lula da Silva, em 2008, que estabelece o ensino de história e cultura afro-brasileira e indígena nos estabelecimentos de educação básica públicos e particulares, e baseada nas teorias da afrocentricidade (ASANTE, 2009) e do indigenismo (ALVES, 2020).

A ideia de afrocentricidade, cunhada pelo professor e pesquisador norte-americano Molefi Asante (2009), reconhecido por ter sistematizado o conhecimento que já estava presente na obra de diversos autores negros pan-africanistas, como Marcus Garvey, Aimé Cesaire, Amilcar Cabral e Abdias Nascimento, tem influenciado de forma decisiva os estudos africanos e africanistas ao redor do mundo. Para Asante, a afrocentricidade "é um tipo de pensamento, prática e perspectiva que percebe os africanos como sujeitos e agentes de fenômeno atuando sobre a sua própria imagem cultural e de acordo com seus próprios interesses humanos" (ASANTE, 2009, p. 93). Asante ressalta que os sujeitos africanos (do continente e diáspora) foram descentrados pela perspectiva eurocêntrica que avançou com o processo de colonização, isto é, um sujeito está descentrado sempre que se posicionar a partir de uma experiência que não está alicerçada em sua própria história. Para entender esse descentramento é preciso levar em conta o que o autor chama de localização, que "no sentido afrocêntrico, refere-se ao lugar psicológico, cultural, histórico ou individual ocupado por uma pessoa em dado momento da história" (ASANTE, 2009, p. 96). Tendo sido os africanos deslocados em termos culturais, psicológicos, econômicos e histórico fazse necessário "que qualquer avaliação de suas condições em qualquer país seja feita com base em uma localização centrada na África e sua diáspora" (ASANTE, 2009, p. 39). Ainda segundo o teórico, a afrocentricidade está estruturada em dois conceitos centrais: conscientização e agência. A conscientização é 0 aspecto que orienta os seres humanos no conhecimento sobre as opressões que sofrem, como também sobre as vias possíveis de libertação através de sua agência. Entende-se agência, por sua vez, como "a capacidade de dispor dos recursos psicológicos e culturais necessários para o 
avanço da liberdade humana" (ASANTE, 2009, p. 94). Asante ressalta que é necessário que o sujeito africano (e afrodescendente), através da conscientização, deixe a posição de dependência (ou desagência) para posicionar-se como agente de transformação para si mesmo e para os seus povos.

Já o indigenismo é uma doutrina, formulada inicialmente no México como parte do movimento intelectual nacionalista, caracterizada pela defesa e valorização das populações indígenas de um país ou região (ALVES, 2020). O marco histórico do indigenismo foi $01^{\circ}$ Congresso Indigenista Interamericano, realizado no México, em 1940, quando os princípios e metas a serem transformados em práticas ou políticas indigenistas foram formulados pelos países do continente americano e questões, como a própria definição do termo "indígena" e de seus correlatos, "índio", "indianismo", foram debatidas (ALVES, 2020). Neste caso, diversos pensadores do campo da Antropologia, como o antropólogo mexicano Guillermo Bonfil Batalla (1992), afirmam que estas expressões designam os colonizados, ou seja, fazem referência direta à relação colonial. Muitos deles acreditam que nas atuais formas de colonização, os neocolonizadores continuam racionalizando e justificado a dominação desses povos e garantindo sua posição de privilégio, a partir dessas categorizações, por exemplo, mascarando a diversidade dos povos originários. Por outro lado, há aqueles que defendam o uso dessas terminologias, que foram ressignificadas pelos próprios sujeitos marginalizados como signo da identidade e da luta. Além disso, outros desafios são recorrentes do indigenismo na contemporaneidade, como aponta Alcida Rita Ramos (2020): as leis aprovadas pelo Estado nacional que protegem os direitos indígenas, mas que são desrespeitadas pelo próprio Estado, com ações que são manifestamente anti-indígenas, a exemplo da falta de investimento adequado em educação indígena; a atuação da Igreja católica progressista que propõe que seus missionários respeitem os costumes indígenas, mas com o propósito de transformar os indígenas em cristãos; as ações das organizações não-governamentais nacionais e estrangeiras que advogam em favor dos direitos indígenas, contanto que eles se comportem de acordo com as expectativas dos apoiadores brancos (RAMOS, 2020).

Todo o processo pedagógico sugerido nessa proposta utilizarão ferramentas on-line, familiarmente acessadas pelo público em geral, como as plataformas de reprodução de vídeos, os aplicativos de trocas de mensagens eletrônicas e os correios de mensagens eletrônicas, para atender às demandas do trabalho educacional remoto, ao se levar em consideração o contexto de pandemia da Covid-19, ao longo do ano de 2020, contudo, podem também ser agregadas à atividade presencial, na sala de aula tradicional, quando toda essa situação for normalizada.

Sabe-se que o conhecimento produzido com fins educativos, principalmente, antes do desenvolvimento das novas tecnologias de informação e comunicação (TICs) era possível, principalmente, através dos livros, enciclopédias e compêndios impressos. Nas duas primeiras décadas 
do século XXI, entretanto, esse quadro tem mudado através de novos suportes e ferramentas e da digitalização de suportes didáticos antigos, agora também disponíveis de forma mais rápida, dinâmica e barata. Segundo especialistas na área, como Nelson Pretto e Alessandra Assis (2008, p. 78), o uso das redes sociais na educação, além de melhores condições de acesso aos conteúdos, também fortalece a interação entre professores e estudantes, criando um elo extraclasse. Nesse sentido, é fundamental considerar que a maioria dos estudantes brasileiros não dispõem de recursos (técnicos, instrucionais) ou contexto social favorável para acompanhar as atividades educacionais on-line. Então, para minimizar os efeitos dessa assimetria é necessário disponibilizar um ambiente virtual que será um espaço agregador de informações, permitindo a hospedagem de todo o conteúdo (textos, vídeos, áudios etc.) já produzido e a ser produzido, incluindo as transmissões ao vivo (lives), ou seja, todo o conteúdo poderá ser consultado a qualquer tempo e a comunidade escolar terá acesso no momento que lhe pareça oportuno.

0 interesse por esse tema surgiu em decorrência de minha atividade profissional como pesquisador na área de Educação, a partir da leitura dos autores citados, e como docente negro que atuou na rede pública de ensino básico e colabora na formação de docentes em cursos de graduação e de pós-graduação em Letras e Pedagogia. É muito comum os professores considerarem os aparelhos eletrônicos, celulares ou smartphones, como inimigos do processo ensino-aprendizagem, por terem que disputar a atenção dos estudantes, entretanto, acredita-se que esses suportes podem ser verdadeiros aliados desses profissionais, pois justamente atraem a curiosidade e 0 interesse dos estudantes, além de fazerem parte do dia a dia da maioria. A utilização de recursos tecnológicos com objetivos educacionais é uma longa e antiga discussão que, desde sempre, exigiu maior aprofundamento e cuidado, mas que, certamente o recente cenário de distanciamento social resultante da pandemia mundial de Covid-19, acelerou e/ou atropelou o processo de aplicação dessas ferramentas nas diferenciadas instituições de ensino, público e privado, básico, tecnológico e universitário, para suprir, minimamente, as atividades pedagógicas, comumente presenciais. Por isso, o momento é propício para tentar tornar essas tecnologias parceiras eficientes do ensino, seja à distância, nos cursos semipresenciais ou presenciais.

\section{Estrutura da proposta de ensino de Língua Portuguesa}

Na educação escolar, os materiais pedagógicos impressos, como o livro didático, por exemplo, são muito utilizados pelos professores da educação básica, principalmente nas escolas públicas, mesmo com a advento das novas tecnologias de informação e de comunicação. Na maioria das vezes, o livro 
didático constitui-se na principal fonte de estudo para os estudantes oriundos das classes mais populares, que não costumam comprar jornais e revistas impressos ou têm dificuldades de acessar à internet, servindo como quase único recurso de leitura e de aprendizagem nas suas casas. 0 livro didático também é importante por seu aspecto político e cultural, na medida em que reproduz e representa os valores da sociedade em relação à sua visão da ciência, da história, da interpretação dos fatos e do próprio processo de transmissão do conhecimento. Diante disso, é fundamental que manuais como esses, além da qualidade e veracidade dos conteúdos, atendam às necessidades de um público diversificado, dedicando-se a temas e questões multiculturais e pluridiscursivas. Entretanto, não é difícil constatar que, de um modo geral, ele ainda omite ou apresenta, de uma maneira simplificada e deturpada, através dos estereótipos, a nível de ilustração, as narrativas histórico-culturais, o cotidiano e as experiências de populações africanas, afro-brasileiras e indígenas, dando continuidade ao longo processo que fortaleceu a chamada supremacia branca no Brasil. Durante décadas sujeitos negros e indígenas foram rotulados em textos e imagens como selvagens, primitivos, maus, demonizados, imorais, exóticos e lascivos, sem qualquer problematização na abordagem disso. Diversos pesquisadores brasileiros, como Norma Abreu Telles, Regina Paim Pinto, Nelson Pretto, Ana Célia da Silva, Luis Alberto Gonçalves e Jonatas Conceição da Silva, já realizaram importantes estudos sobre a estereotipia nos livros didáticos e comprovaram que muitos desses estudantes ainda não se sentem satisfatoriamente contemplados na educação escolar, e, especificamente em relação ao livro didático, eles não se enxergam e não se reconhecem etnicamente naquilo que normalmente é representado nessas obras. Para a pesquisadora Ana Célia Silva (2005), por exemplo, ao veicular estereótipos que expandem uma representação negativa do negro e do indígena e uma representação positiva do branco, o livro didático está

expandindo a ideologia do branqueamento, que se alimenta das ideologias, das teorias e estereótipos de inferioridade/superioridade raciais, que se conjugam com a não legitimação pelo Estado, dos processos civilizatórios indígena e africano, entre outros, constituintes da identidade cultural da nação. (SILVA, 2005, p. 23)

Além disso, o apagamento e veiculação de estereótipos nos livros didáticos pode contribuir ainda mais na exclusão e na cristalização desses sujeitos em funções e papéis estigmatizados pela sociedade, na autorrejeição e na baixa autoestima, dificultando ainda mais a organização política desses grupos estigmatizados. 0 professor, inclusive, também pode vir a ser um mediador inconsciente desses discursos, se for formado por uma visão acritíca das instituições, das práticas pedagógicas e por uma 
ciência tecnicista e positivista, que não contempla outras possíveis formas de conhecimento, de ação e de reflexão.

Assim, no intuito de amenizar essa situação, a presente proposta pedagógica inclui a elaboração coletiva de um material didático, constituído por uma criteriosa seleção de textos e autores, em sua maioria contemporâneos, com atividades de leitura, compreensão de textos, comunicação oral e escrita e produção de vídeos. Na educação escolar presencial, ele também pode servir como complemento ao livro didático adotado na escola, preenchendo as possíveis lacunas que o livro didático possa apresentar. Para contemplar as trajetórias históricas e experiências socioculturais dos povos afro-descendentes e indígenas, de uma forma não estereotipada, o material que aqui apresentamos abrange os seguintes temas de estudo: História da África pré-colonial; História da América pré-colonial, Geografia da África; A escravidão mercantil na África e no Brasil; A colonização brasileira e os povos indígenas; As formas de resistência à escravidão mercantil; A abolição da escravatura no Brasil; O negro na sociedade brasileira após a escravidão; A luta antirracista e os movimentos negros e indigenistas; $O$ negro e 0 indígena na educação brasileira; Culturas afro-brasileiras; Sociedades e culturas indígenas; Literaturas africanas de língua portuguesa; Literatura Afro-brasileira e Escritores Afro-Brasileiros; Literaturas indígenas; Cosmogonias e religiosidades afro-brasileiras; Cosmogonias e religiosidades indígenas; Racismo estrutural, institucional e recreativo. Todo o material selecionado e produzido será disponibilizado e articulado por meio de ferramentas virtuais: o YouTube, o WhatsApp e o Gmail, por serem mais facilmente utilizadas e acessadas pelo público em geral.

O YouTube é uma ferramenta de mídia digital, criada em 2005 por Steve Chen, Chad Hurley e Jawed Karin, exclusivamente para compartilhamento de vídeos na internet (BURGESS; GREEN, 2009). Em 2006, a Google comprou o site e agora ele funciona como uma de suas subsidiárias. Com vídeos voltados principalmente para entretenimento, a exemplo dos filmes, videoclipes musicais e vídeos humorísticos, essa ferramenta tem sido muito utilizada também para transmitir conhecimento através de videoaulas e tutoriais. De acordo com um levantamento do YouTube Insights (2020), site criado pela própria empresa para apresentar os motivos pelos quais milhões de pessoas cada vez mais se interessam em acessar conteúdos em vídeo, o Brasil representa 98 milhões de usuários mensais na plataforma.

Para Wim Veen e Ben Vrakking (2009), o YouTube é uma ferramenta importante para se pensar a educação na contemporaneidade, que não deve se restringir ao espaço físico e abarcar um leque maior de possibilidades. Outra vantagem de utilizar o YouTube na educação é que é uma ferramenta gratuita e de simples manipulação. Qualquer pessoa pode postar um vídeo ou acessá-lo de forma ainda mais fácil, graças à ferramenta de busca que o site oferece. Para quem ainda não é um usuário do YouTube, basta criar uma conta na rede para ter acesso às listas de reprodução. Elas permitem que cada um 
organize seus vídeos favoritos em sequência. O usuário também não precisa selecionar apenas vídeos publicados por ele, sua lista de reprodução pode conter vídeos publicados por outros membros do YouTube. Ao criar listas de reprodução específicas para os principais assuntos abordados em sala de aula, o professor cumpre o papel do mediador e oferece aos estudantes a oportunidade de aprofundar os conhecimentos a respeito dos temas trabalhados nas aulas. Ao organizar listas de reprodução com vídeos confiáveis e relevantes, o professor sugere conteúdos que possam ser acessados pelos estudantes, mas também incentiva que eles busquem e selecionem informações, de acordo com seus interesses e necessidades. Os estudantes também podem expor suas dúvidas no espaço de comentários do canal, logo abaixo dos vídeos.

O WhatsApp, por sua vez, é um aplicativo multiplataforma de mensagens instantâneas e chamadas de voz para smartphones, lançado em 2009 por Brian Acton e Jan Koum, na California, Estados Unidos. Além de mensagens de texto, os usuários podem enviar imagens, vídeos e documentos em Portable Document Format (PDF, em português, Formato Portátil de Documento), além de fazer ligações gratuitas por meio de uma conexão com a internet. Essa ferramenta de comunicação virtual está cada vez mais inserida no cotidiano familiar e social, por isso pode e deve ser utilizada também no ambiente escolar. Nessa proposta de ensino, o WhatsApp pode ser utilizado para incentivar a comunicação oral durante os debates, através do compartilhamento de mensagens de áudios, possibilitando que todos produzam e compartilhem informação e exponham suas opiniões sobre determinado assunto.

Entre as opções de e-mail, optou-se pelo Google Mail (mais conhecido como Gmail), que é um serviço gratuito de webmail criado pela Google, em 2004, devido ao grande espaço de armazenamento (1GB), o espaço permitido para anexos (25MB por mensagem) e ferramentas (como o Google Drive para Windows) que possibilitam utilizar a conta do serviço como se fosse um disco virtual. Ele servirá para receber e arquivar as atividades escritas produzidas pelos alunos e compartilhar o material escrito produzido, com textos verbais, textos mistos, fotografias e imagens, hiperlinks.

Vale ressaltar que a produção do conhecimento ou mesmo o compartilhamento dele, dentro dessa proposta, exigirá de todos os participantes do processo, além de acesso tecnológico, uma inserção maior nas ferramentas sugeridas, tornando-se mais comum sua presença no meio virtual, e habilidades no manuseio dessas interfaces. Os recursos escolhidos também exigem que todo o trabalho indicado seja desenvolvido grupos, de, no máximo, vinte pessoas, para que não haja uma sobrecarga de conteúdos e atividades, e para facilitar o suporte técnico, quando necessário. 


\section{Seleção e produção de conteúdo via internet}

As atividades sugeridas nessa proposta visam atender diferentes gêneros e tipologias textuais, a serem organizados em cinco grupos: literários, jornalísticos, imagéticos, audiovisuais e musicais.

\subsection{Gêneros literários}

Os textos selecionados e atividades delineadas para o desenvolvimento dessa proposta pretendem explorar temas que estimulem a reflexão e o debate sobre questões relacionadas às histórias e culturas africana, afro-brasileira e indígenas, além do desenvolvimento das relações étnico-raciais no Brasil ao longo de sua história. Entre os textos poéticos e narrativos, alguns nomes de escritores e escritoras contemporâneos são: Manoel Rui, Paula Tavares e Ondjaki, de Angola; José Craveirinha, Noêmia de Souza e Luís Bernardo Honwana, de Moçambique; Solano Trindade, Oliveira Silveira, Geni Mariano Guimarães, Cuti, Éle Semog, Conceição Evaristo, Mãe Stella de Oxóssi, Carolina Maria de Jesus, Daniel Munduruku, Davi Kopenawa, Eliane Potiguara, do Brasil, extraídos de coletâneas literárias variadas, a exemplo da coleção Cadernos Negros. Em relação à dramaturgia, a cena teatral negrobrasileira contemporânea também representa não só mais uma das ações de combate ao racismo, com discussões sobre colorismo e clamores por representatividade, visibilidade e participação no mercado, como espaço de experimentação e de reconfiguração estética. Para tal, a indicação de trabalho é o livro Dramaturgia negra (2019), coletânea de textos dramatúrgicos organizada por Eugênio Lima e Julio Ludemir.

Entre as habilidades a serem desenvolvidas nessa seção, destacam-se a leitura, a compreensão e a produção de textos. Torna-se relevante ressaltar, nesse aspecto, que as experiências de ensino e aprendizagem em comunidades afro-brasileiras e sociedades indígenas normalmente se orientam por outras variadas lógicas, diferentes daquelas pautadas pelo grafocentrismo, logocentrismo e etnocentrismo, que normatizam a constituição dos saberes tradicionais ocidentais (KRESS; LEEWEN, 2001). Assim, espera-se, no geral, o desenvolvimento de habilidades intelectuais de reflexão, interpretação, análise e síntese que respeitem e valorizem essas particularidades. Para isso, algumas estratégias são sugeridas, como leitura individual dos textos previamente disponibilizados por e-mail; discussão dirigida, envolvendo toda a turma no grupo do WhatsApp, sob a mediação do professor, exposição das respostas em forma de painel, quando elas resultarem de trabalho em equipe, ou seja, os relatores de cada equipe apresentam as respostas a cada questão; ou exposição individual. Em relação à leitura de livros na íntegra, o importante é que o principal objetivo seja que o estudante tenha o gosto 
pela leitura estimulado. Dessa forma, sugere-se discussão em grupos constituídos de estudantes que leram o mesmo livro (opiniões a respeito do livro, de suas personagens, partes consideradas mais interessantes etc.); exposição de estudantes sobre os livros que leram, aconselhando (ou desaconselhando) a leitura aos colegas, através de resenhas, publicidade e vídeo etc.; júri on-line simulado, em que um livro é julgado (os que gostaram do livro fazem sua defesa, os que não gostaram fazem a acusação); atividades de criação, a partir da leitura, como resumir o livro até determinado ponto e imaginar um desenlace diferente (exercício oral ou escrito, individual ou em grupo); criar um cartaz de publicidade, anunciando o livro e estimulando sua leitura (trabalho individual ou em grupos); escrever um e-mail ao autor da obra, fazendo perguntas ou reclamando contra o destino dado a uma personagem (ou, em vez de carta, escrever um diálogo imaginário com o autor da obra); escrever um e-mail a uma personagem da obra, ou um diálogo imaginário com uma personagem da obra; escrever um e-mail imaginário de uma personagem da obra ao autor, falando do destino que lhe foi dado; determinar (oralmente ou por escrito) se gostaria de viver no ambiente em que se passa a história e por quê; dramatizar partes da obra e produzir um vídeo etc.

Para os textos escritos produzidos pelos próprios estudantes, deve-se observar que as subjetividades, sentimentos e situação sociocultural, principalmente dos estudantes negros e indígenas, não costumam estar desapartadas das suas escritas, isto é, as suas histórias de vida configuram-se como um dos elementos motivadores e intensificadores nas suas escrituras, assim, tanto as especificidades quanto as particularidades pessoais devem ser respeitadas em suas diferenças. A escritora Conceição Evaristo, refletindo sobre o conceito de "escrevivência" (2020), considera que o sujeito da literatura negra tem a sua existência marcada por sua relação e por sua cumplicidade com outros sujeitos. Assim, esse processo se dá em um espaço aberto entre a invenção e o fato, utilizandose dessa profundidade para construir uma narrativa singular, mas que aponta para uma coletividade. Entretanto, podem ser requisitados, além da sistematização da experiência de escrita individual e coletiva do grupo, produção de textos com base em pressupostos teóricos da Linguística Textual, da Linguística Aplicada, da Sociolinguística e dos Estudos Literários Contemporâneos, com vistas à documentação e sistematização de todo o processo, para consolidar noções e conceitos tratados ao longo do curso, para incentivar os estudantes a usar a escrita como forma de comunicação e de interlocução, em diferentes contextos, e desenvolver neles as habilidades de uso adequado da escrita como forma de comunicação e de interlocução, em cada situação específica. 


\subsection{Gênero jornalístico}

A imprensa tem um papel imprescindível em uma sociedade democrática, por isso, torna-se necessário promover atividades de ensino que promovam a formação de leitores mais críticos dessas informações, tornando-os mais capazes de analisar os discursos explícitos e implícitos veiculados por toda a mídia, e possibilitando-os de atuar mais adequadamente dentro da sociedade (OBSERVATÓRIO, 2020). Em sala de aula, é possível utilizar a imprensa em quatro formas diferentes de abordagem: como um recurso didático, como um objeto de estudo, como uma técnica de trabalho em aula ou como um elemento de inferência do currículo (OBSERVATÓRIO, 2020). Como objeto de estudo, propõe-se uma investigação sobre o desenvolvimento da imprensa negra no Brasil junto aos estudantes. Quantos jornais e revistas foram produzidos ao longo da história, quais as principais publicações, temas mais recorrentes nas reportagens etc. A existência de uma imprensa negra no Brasil é fundamental em termos de representatividade, assim como um modo de contrapor o sistema e práticas essencialmente discriminatórias, estabelecendo-se como voz para o povo negro e servindo como veículo e documentação sobre a luta em favor da equidade racial (OBSERVATÓRIO, 2020). Para atender, em sala de aula, outras formas de atuação da imprensa o professor pode promover estudos e discussões a partir de matérias veiculadas em recentes jornais e revistas dedicados ao público negro, como a revista Raça Brasil, além de analisar e promover debates a partir de crônicas e artigos de opinião, como os produzidos pelas escritoras Cidinha da Silva e Djamila Ribeiro, publicados em diferentes revistas e periódicos. Os estudantes também podem produzir reportagens com temas selecionados por eles e fatos ocorridos em suas comunidades, a serem veiculadas no canal do YouTube, e compartilhadas por e-mail.

\subsection{Gêneros imagéticos}

0 uso de imagens, que apresentam elementos relacionados às iconografias, estéticas e simbologias afrodiaspóricas e indígenas, a exemplo das marcas étnicas, como as escarificações, dos penteados, dos signos e símbolos comunicacionais e religiosos, também pode ser muito eficiente para o desenvolvimento de um ensino antirracista. De acordo com a pesquisadora Suely Santos Souza (2014, p. 81),

as imagens apresentam extrema competência para a transmissão de conteúdos culturais e ideológicos, através de reflexão e associações. Esses aspectos serão interiorizados, produzindo e reproduzindo as ideias que eles difundem, pois "há emoção, há manifestação e 
apelo aos sentimentos [...] mexem diretamente com o receptor e põem em questionamento a posição deste em relação ao tema" (Idem, p. 68). (SOUZA, 2014, p. 81)

Nesta proposta, recomenda-se, por exemplo, o trabalho com os grafismos indígenas e os adinkras, símbolos ideográficos dos povos acã, que ocupam a região África Ocidental que hoje abrange parte de Gana e da Costa do Marfim. Os estudiosos Eliza Nascimento e Luiz Carlos Sá, autores do livro Adinkra: sabedoria em símbolos africanos (2009), afirmam que os adinkras são extremamente importantes para as sociedades africanas porque incorporam, preservam e transmitem aspectos da história, da filosofia, dos valores e das normas socioculturais dessas populações, e vêm sendo adotados na diáspora como parte da missão de recuperar e valorizar essas antigas tradições que compõem o legado ancestral africano.

Nas artes visuais, uma indicação de obra é o catálogo da exposição Histórias Afro-Atlânticas, que reúne imagens de produções de artistas negros contemporâneos. Concebida para celebrar os 130 anos da Abolição da escravidão negra no Brasil, completados em 13 de maio de 2018, Histórias AfroAtlânticas, que esteve em cartaz no Museu de Arte de São Paulo e no Instituto Tomie Otake, na cidade de São Paulo, entre os dias 29 de junho e 21 de outubro de 2018, ao reunir mais de quatrocentos trabalhos de artistas de diferentes lugares do mundo, vários deles envolvidos com questões afrodescendentes, como memória e ancestralidade, a exemplo dos brasileiros Jaime Lauriano, Emanoel Araújo, Rosana Paulino, Flavio Cerqueira, Tiago Sant'anna e Sônia Gomes, visou escapar de narrativas eurocêntricas na história da arte, ampliar conceitos e linguagens, para além de temas e imagens, diante das histórias pluriversais e polifônicas, conversar com a busca da identidade negra no Brasil e nas Américas, e também dialogar com os esforços da cultura e entretenimento popular em buscarem retratar a subjetividade negra de maneiras fidedignas. Entre os artistas indígenas, a proposta visa desenvolver atividades a partir do trabalho de Jaider Esbell e Arissana Pataxó. Estão incluídas também, nessa subseção, atividades com charges, a exemplo das produzidas por Maurício Pestana. Todas as imagens selecionadas podem ser analisadas em seus contextos históricos e de produção, pelas temáticas empregadas e possibilidades estéticas.

\subsection{Gêneros audiovisuais}

Em relação à utilização de vídeos e filmes como recurso didático do qual o professor pode dispor, há uma série de conteúdos já disponibilizados no YouTube, como videoaulas, entrevistas, palestras, videoclipes etc., que podem ser indicados através das listas de reprodução. Uma sugestão é desenvolver 
atividades a partir de vídeos de influenciadores digitais negros, como Spartakus e AD Junior, disponíveis em seus respectivos canais do YouTube, que abordem diferentes questões das populações afrobrasileiras. Para isso, algumas recomendações devem ser seguidas tanto pelos professores quanto pelos outros colaboradores na seleção de conteúdo. É preciso analisar o contexto, a linguagem e o enredo para a escolha do material mais adequado, principalmente levando-se em consideração a faixa etária dos estudantes; verificar a qualidade do áudio e do vídeo, testando-o em diferentes equipamentos (smartphone, notebook, televisão), observar a duração do tempo do vídeo (evitar, por exemplo, vídeos muito longos, com exceção de filmes, que podem ser indicados esporadicamente), observar se as imagens despertarão a criticidade e reflexão; verificar as condições de acesso dos estudantes aos equipamentos e qualidade da internet para acessar esses conteúdos (caso não haja internet, ou ela seja de péssima qualidade, o que inviabilizaria a reprodução do vídeo, pode-se fazer o download do material e enviar aos estudantes por e-mail; e elaborar atividades e exercícios que busquem contextualizar com 0 vídeo sugerido.

Para produção e disponibilização de conteúdos próprios, a ideia é criar um canal específico no YouTube para atender às demandas do curso, disponibilizando os links aos estudantes, via e-mail ou WhatsApp, e sugerir inscrição aos que possuam conta no site. Além dos conteúdos já disponíveis no YouTube, que serão selecionados de acordo com os interesses e necessidades do grupo, deve-se produzir novos conteúdos exclusivos para o canal, como videoaulas planejadas e desenvolvidas pelo professor. Os conteúdos produzidos pelos estudantes também podem ser disponibilizados na rede, desde que os pais e responsáveis sejam comunicados previamente para autorizar a exibição da imagem dos filhos no canal. Tal ação pode incentivar os estudantes a participar de forma mais ativa das atividades do curso. No caso dos vídeos produzidos por outrem, é necessário atribuir créditos a essa autoria.

As produções audiovisuais do cinema também serão utilizadas nesta proposta. $O$ cinema negro brasileiro, entre outros aspectos, tem se configurado como um campo de luta por visibilidade das populações afro-brasileiras, onde se conjugam várias experiências da arte e da luta política para romper a discriminação, o racismo, a invisibilidade e reafirmar a identidade negra. Assim, ao longo da história do cinema no Brasil, diferentes cineastas negros e negras, principalmente a partir da década de 1960, atuaram na produção de filmes que ressaltam o protagonismo do negro e desconstrói estereótipos. Interessados nas questões políticas e identitárias, realizadores e realizadoras negros, como Zózimo Bulbul, Joel Zito Araújo, Jeferson De, Lilian Solá Santiago, Viviane Ferreira, Renata Martins, Yasmin Thainá, Larissa Fulana de Tal, Juliana Vicente, entre outros e outras, têm encontrado no documentário e no curta-metragem de ficção espaços estratégicos para tornar cada vez mais visíveis suas pautas, de forma direta e indireta. Algumas indicações são os documentários A negação do Brasil (2001), dirigido 
por Joel Zito Araújo, Raça (2013), dirigido por Joel Zito Araújo e Megan Mylan, Dê sua ideia, debata (2007), dirigido por Viviane Ferreira, e o curta-metragem de ficção 0 dia de Jerusa (2015), também dirigido por Viviane Ferreira, que abordam temas como racismo nos meios de comunicação, identidade negra, memória e relações humanas. Já os cinemas indígenas produzidos no Brasil, além de representarem um importante instrumento de luta, criação e reflexão, defendendo e construindo lugares de fala, atualizam as heranças ancestrais às expressões contemporâneas, com referências locais e globais. Um exemplo disso é o projeto Vídeo nas aldeias, fundado em 1986, que objetiva formar diretores cinematográficos indígenas e permitir que eles utilizem recursos audiovisuais para fortalecer suas identidades, culturas e memórias. Esse projeto já conta com um acervo de mais de setenta filmes, muitos premiados nacional e internacionalmente, sendo que, pelo menos, metade é de autoria dos próprios indígenas.

\subsection{Gêneros musicais}

Muitos estudiosos também têm identificado nas musicalidades brasileiras, um dos mais importantes aspectos das culturas de origem africana e indígena, recursos significativos para o trabalho da oralidade na educação. Diferentes trabalhos, como o de Elaine Nunes de Andrade, organizadora do livro Rap e educação, rap é educação (1999), têm buscado evidenciar práticas pedagógicas em que o fazer musical tem papel privilegiado, por exemplo, no ensino das populações negras no Brasil. Nesse sentido, fazer música pode ser entendido como uma forma de retomar, reinventar, dar um sentido positivo à própria vida. É o que muitos jovens têm feito por meio do rap. Conforme Elaine Nunes de Andrade (1999), ele pode ser definido como um estilo musical que combina elementos da modernidade tecnológica com a oralidade. A presença da oralidade, nas letras de rap, é um traço marcante de africanidade. Uma sugestão é trabalhar com o disco "Sobre Crianças, quadris, pesadelos e lições de casa" (2015), do rapper Emicida e canções dos rappers indígenas Wera e Kaê Guajajara, analisando contextos históricos e de produção, temáticas abordadas e referências musicais.

\section{Estratégias de avaliação}

As estratégias de avaliação aqui propostas precisam ser vistas como um processo contínuo, individual e coletivo, que visem acompanhar todas as etapas do processo formativo dos sujeitos envolvidos. Em decorrência do formato on-line, os critérios não podem ser os mesmo de uma situação presencial, observando-se, por exemplo, o processo de adaptação dos estudantes, as dificuldades 
técnicas e de acessibilidade e o aspecto emocional. A autoavaliação, por exemplo, é um momento importante no processo de aprendizagem significativa, uma situação na qual o estudante desenvolve estratégias de análise, interpreta suas produções e avalia diferentes procedimentos. Esse aprendizado é essencial para a construção da autonomia dele, porque contribui para a objetividade desejada na avaliação, que só poderá ser construída com a coordenação dos diferentes pontos de vista, tanto dos estudantes quanto do professor.

\section{Considerações finais}

Os desafios do Estado brasileiro para o estabelecimento de um modelo de educação democrática, pluricultural e antirracista ainda são enormes, não só na garantia do direito ao acesso e a permanência dos estudantes negros e indígenas em todos os níveis de educação escolar, como no investimento em formação de professores, produção de material didático e oferta de tecnologias digitais a serviço do ensino, com ênfase na abordagem dos propósitos postulados na Lei 11.645-08.

Sabe-se que o projeto de extermínio dos povos afrodescendentes e indígenas no Brasil, iniciado desde os tempos da colonização portuguesa e da escravização africana, não está apenas localizado no espaço do corpo. Genocídio pode ser entendido também enquanto prática política de aniquilamento das histórias, memórias e conhecimentos desses grupos, denominada epistemicídio, ou seja, através do silenciamento, apagamento e exclusão de suas palavras e de suas ideias pelo poder hegemônico e sua ordem do discurso. Assim, em uma visão eurocêntrica, pressupôs-se, entre outros aspectos, que esses sujeitos não eram habilitados intelectualmente ou que não possuíam educação, pelo simples fato de não seguirem os mesmos modelos educacionais ocidentais. Foi com esse ponto de vista que historicamente negou-se o seu acesso, principalmente em relação aos negros, ou se implantou projetos de educação escolar inadequados, como do caso dos povos indígenas. Durante séculos, a educação escolar oferecida a eles teve o objetivo de integrá-los à sociedade nacional, contudo, sem respeito às suas diferenças culturais e linguísticas, em um modelo de educação brancocêntrica, cuja cultura do branco servia de referência para os indígenas. Em outras palavras, a escola servia para o branco ensinar ao indígena a ser e a viver como ele. Por isso, no intuito de reverter essa situação, propostas, como a apresentada nesse artigo, são pertinentes e necessárias.

\section{Referências}

ANDRADE, Elaine Nunes de. Rap e educação, rap é educação. São Paulo: Summus, 1999. 
ASANTE, Molefi Kete. Afrocentricidade: notas sobre uma posição disciplinar. In: NASCIMENTO, Elisa L. (org.). Afrocentricidade: uma abordagem epistemológica inovadora. SP: Selo Negro, 2009.

ALVES, Jean Paraizo. Indigenismo e políticas indigenistas em dois países americanos (Brasil e México). Disponível em: https://periodicos.unb.br/index.php/interethnica/article/download/11883/10423/. Acesso 20 mai. 2020.

BONFIL BATALLA, Guillermo. El concepto de indio en América: una categoría de la situación colonial. In: Identidad y pluralismo cultural en América Latina. San Juan: Universidad de Puerto Rico, 1992. p. 2548.

BURGESS, Jean. GREEN, Joshua. YouTube e a Revolução Digital: como o maior fenômeno da cultura participativa transformou a mídia e a sociedade. Tradução de Ricardo Giassetti. São Paulo: Aleph, 2009.

EVARISTO, Conceição. "Minha escrita é contaminada pela condição de mulher negra". Entrevista a Nexo Jornal, 26 mai. 2017.2 Disponível https://www.nexojornal.com.br/entrevista/2017/05/26/Concei\%C3\%A7\%C3\%A3o-Evaristo\%E2\%80\%98minha-escrita-\%C3\%A9-contaminada-pela-condi\%C3\%A7\%C3\%A3o-de-mulhernegra\%E2\%80\%99. Acesso em 3 mai. 2020.

HISTÓRIAS afro-atlânticas: vol. 1. Organização editorial, Adriano Pedrosa, Tomás Toledo. São Paulo: MASP: Instituto Tomie Ohtake, 2018.

KRESS, Gunther; LEEUWEN, Theo Van. Multimodal discourse: the modes and media of contemporary communication. New York: Oxford University, 2001.

NASCIMENTO, Elisa Larkin; SÁ, Luiz Carlos. Adinkra: sabedoria em símbolos africanos. Rio de Janeiro: Pallas, Ipeafro, 2009.

OBSERVATÓRIO da Imprensa. Equidade racial: memória da imprensa negra no Brasil. Disponível em: http://www.observatoriodaimprensa.com.br/equidade-racial/memoria-da-imprensa-negra-no-brasil/.

Acesso em 7 mai. 2020.

PRETTO, Nelson de Luca; ASSIS, Alessandra. Cultura digital e educação: redes já. In: PRETTO, Nelson de Luca; SILVEIRA, Sergio Amadeu da (org.). Além das redes de colaboração: internet, diversidade cultural e tecnologias do poder. Salvador: EDUFBA, 2008. p. 75-84.

RAMOS, Alcida Rita. Indigenismo: um orientalismo americano. Anuário Antropológico [On-line], I| 2012. Disponivel em: http://journals.openedition.org/aa/268. Acesso em 14 out. 2020.

SILVA, Ana Célia da. A desconstrução da discriminação do negro no livro didático. In: MUNANGA, Kabengele (org.). Superando o racismo na escola. 2 ed. rev. Brasília: Ministério da Educação, Secretaria de Educação Continuada, Alfabetização e Diversidade, 2005. p. 21-38.

SOUZA, Suely dos Santos. O livro didático e as influências ideológicas das imagens: por uma educação que contemple a diversidade social e cultural. Dissertação de Mestrado, Programa de Pós-Graduação em Educação da Universidade Estadual de Feira de Santana. Orientadora: Glaucia Maria Costa Trinchão. Feira de Santana, 2014. Disponível em: Acesso: 9 mai. 2020. 
VEEN, Win; VRAKKING, Ben. Homo zappiens: educando na era digital. Porto Alegre: Artmed, 2009.

YOUTUBE INSIGHTS. Disponível em https://youtubeinsights.withgoogle.com/. Acesso em 7 mai. 2020.

Data de submissão: 06/06/2020. Data de aprovação: 23/10/2020. 